\title{
Spina Bifida and Rehabilitation
}

\author{
Nihal ÖZARAS \\ Department of Physical Medicine and Rehabilitation, Bezmialem Vakıf University Faculty of Medicine, Istanbul, Turkey
}

\begin{abstract}
Spina bifida (SB) is the incomplete closure of the posterior elements of the vertebrae due to a developmental disorder. Among the causes of childhood disability, SB is the second most common cause after cerebral palsy. Generally, secondary motor neuron findings are seen below the lesion.The ambulation grade and the orthoses used by patients vary according to the level of the lesion. SB patients experience various complications throughout their lives. The purpose of SB rehabilitation is to prevent these complications and to keep the patient's functional status at the best possible level. Therefore, a rehabilitation program, starting at infancy and continuing during the lifetime, should be family centered and should be conducted with a multidisciplinary team.

Keywords: Spina bifida, rehabilitation, exercise, orthosis
\end{abstract}

\section{Introduction}

Spina bifida (SB) is the incomplete closure of the posterior components of the vertebrae because of a developmental disorder and the clinical picture that occurs in association with this condition. It is the second most common cause of childhood disability after cerebral palsy. In classical classification, SB has two types: closed (spina bifida occulta, SBO) and open (spina bifida aperta, SBA). Some abnormalities, such as defects in the vertebral components, tufts of hair on the skin, and nevus, are observed in SBO; however, a sac is not observed. In contrast, in SBA, a sac is observed that includes only meninges or neural tissues with meninges; these are called meningocele and myelomeningocele, respectively (Figure 1) (1-3).

\section{Etiopathogenesis}

The neural plaque that develops between the $2^{\text {nd }}$ and $6^{\text {th }}$ weeks in the embryologic stage is closed by curving from two edges and forms the neural tube. While the brain develops from the cranial part of the neural tube, the spinal cord develops from the caudal part. Problems that occur during the closure of the caudal part of the neural tube in this stage cause SB and other spinal cord disorders $(3,4)$. The incidence of $S B$ varies between 0.2 and 10 per 1000 people in different regions of the world; however, it decreases to 0.2 per 1000 people in the USA $(3,5,6)$. In a study conducted in Turkey between 2003 and 2004, 17 SB cases (SBO and SBA) were encountered in 8631 livebirths. On the basis of these data, the incidence can be considered as 1.97 per 1000 people (7).

Genetic factors have an important place in the etiology of $S B$. The incidence of $S B$ is 50 times greater than the general population if the patient has siblings with SB. Genetic predisposition was also demonstrated in twin and family studies. Because the genes included in folate metabolism are believed to be responsible, studies focus on these genes $(3,6)$. However, environmental factors are also important for the development of SB. These factors include the use of drugs, such as carbamazepine, that affect folate metabolism in pregnancy, poorly regulated diabetes, and inflammatory diseases experienced during the first trimester of pregnancy. Many studies have revealed that the use of folic acid before and during pregnancy decreases the incidence of

Address for Correspondence: Dr. Nihal Özaras, Bezmialem Vakıf Üniversitesi Tıp Fakültesi, Fiziksel Tıp ve Rehabilitasyon Anabilim Dalı, İstanbul, Türkiye. Phone: +90 21253469 00-1305 E-mail: nozaras@hotmail.com

Received: March 2014 Accepted: December 2014

OCopyright 2015 by Turkish Society of Physical Medicine and Rehabilitation - Available online at www.ftrdergisi.com

Cite this article as:

Özaras N. Spina Bifida and Rehabilitation. Turk J Phys Med Rehab 2015;61:65-9. 

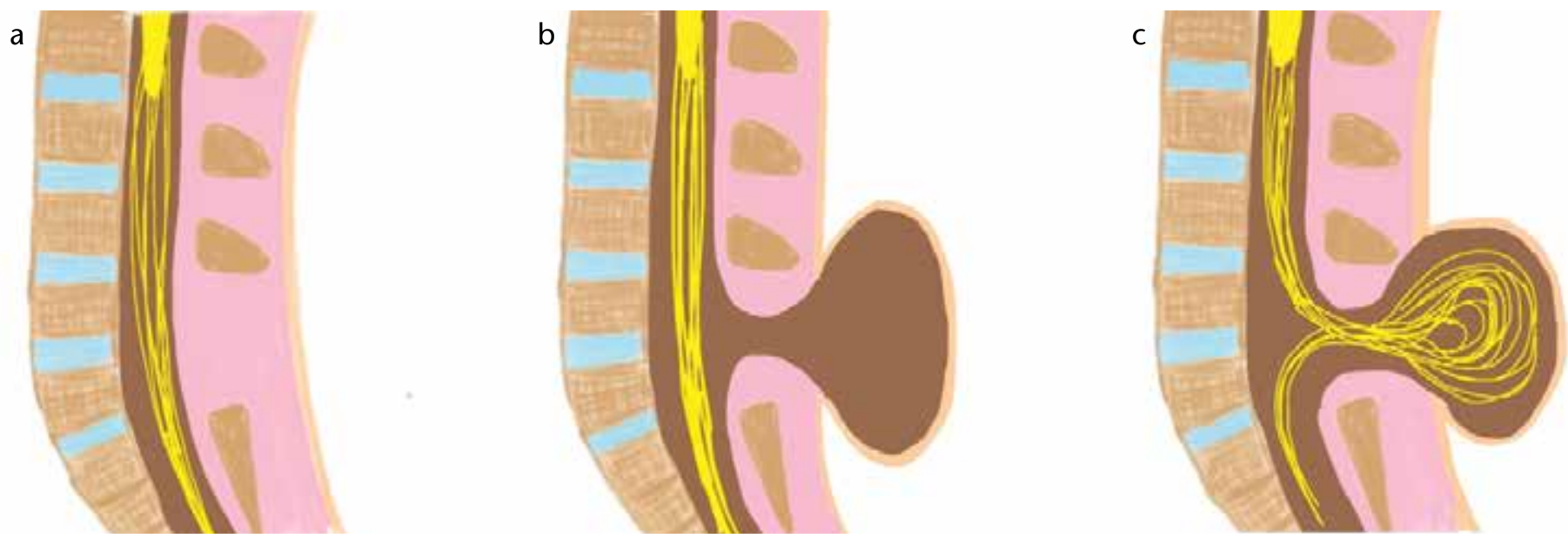

Figure 1. a-c. Spina bifida occulta (a), myelocele (b), and myelomeningocele (c)

SB. It has been found that when a high amount of folic acid is administered to patients with high genetic predisposition, negative genetic effects can be reduced $(3,6,8-10)$.

\section{Fetal Diagnosis and Treatment}

It is possible to detect SB in the fetal stage. A high level of alpha-fetoprotein suggests SB (1). With ultrasound (US) imaging performed in this stage, the diagnosis of SB can be established; the level of lesion can be accurately determined, particularly with three-dimensional US $(11,12)$. In a study conducted in Turkey, it has been observed that a diagnosis is established in the prenatal stage at the rate of $72 \%$ (13). Magnetic resonance imaging (MRI) can provide precise data in situations in which an adequate US image cannot be obtained, such as maternal obesity, presence of oligohydramnios, baby's position, or developed bone structure in advanced fetal age patients (14). In the prenatal stage, a possible clinical course of disease can be estimated by determining the level of lesion and accompanying malformations. Although surgical interventions are performed for babies with SB in the fetal stage in some health centers, it is reported that these interventions pose a risk for mothers and babies, and full recovery is not achieved. Therefore, these operations must be performed in health centers where there are multidisciplinary teams comprising specialists in this area $(15,16)$. While this is a controversial subject, the family should be recommended to receive consultancy service regarding pregnancy termination, particularly in severe cases $(11,14)$.

There are no clear data on whether babies diagnosed with SB during pregnancy must be delivered through a vaginal route or cesarean section. In a study, it has been reported that the neurological level is two-segments lower in babies delivered by cesarean section; a cesarean is often preferred in clinical practice. In contrast, there are also some studies reporting that the delivery method does not affect the neurological level (17-20). Closure of lesions within the first $72 \mathrm{~h}$ after delivery reduces the risk for central nervous system infection and minimizes the occurrence of neurological involvement. Some patients with SB have hydrocephaly, and early intervention can be required. Therefore, it is recommended that babies with SB should be de- livered in a center where there are related specialists, and necessary interventions can be performed as soon as possible under elective conditions $(18,20,21)$.

\section{Clinical Findings and Assessment}

Secondary motor neuron findings, such as decreased deep tendon reflexes, muscle weakness, and hypoesthesia/anesthesia, are generally observed in SB. Vertebral disorders, such as kyphosis and scoliosis, hip dislocation, contractures in the hip and knee, and ankle and foot deformities, can coexist with this clinical picture (Figure 2) $(1,22,23)$.

The physical examination of a patient with SB begins with inspection. The presence of a sac that is open, operated, or covered by a layer of skin on the back, hirsutism, and skin lesions, such as color, change are evaluated; vertebral anomalies, malposition of joints, and deformities are recorded, if any are present. A baby with SB is monitored for some time, and the characteristic of spontaneous motion in the lower extremities is examined. It has been reported that the rate of spontaneous motion in the lower extremities is lower in babies with SB than in healthy babies. The spinous processes are followed with descending palpation; defects or abnormal formations are determined $(24,25)$. The evaluation is completed with neurological and musculoskeletal system examinations, which are performed considering the age of patient.

During the examination, the strengths of the muscles in the lower extremities, which are very important for determining ambulation level, must be evaluated by manual blood test; sensory examination must be comprehensively performed; and neurological level of the lesion must be detected with these findings. Although there are various classification systems for detecting motor involvement in SB, the criteria of the International Myelodysplasia Study Group provide the best demonstration of motor level. In these criteria, each motor level for T10 and lower lesions is defined in detail (for example: for L2, iliopsoas, sartorius, and all hip adductors must have muscle strengths of 3 or higher). Thus, the use of a common language for assessments and a clearer demonstration of clinical status in follow-ups have been enabled (26). 


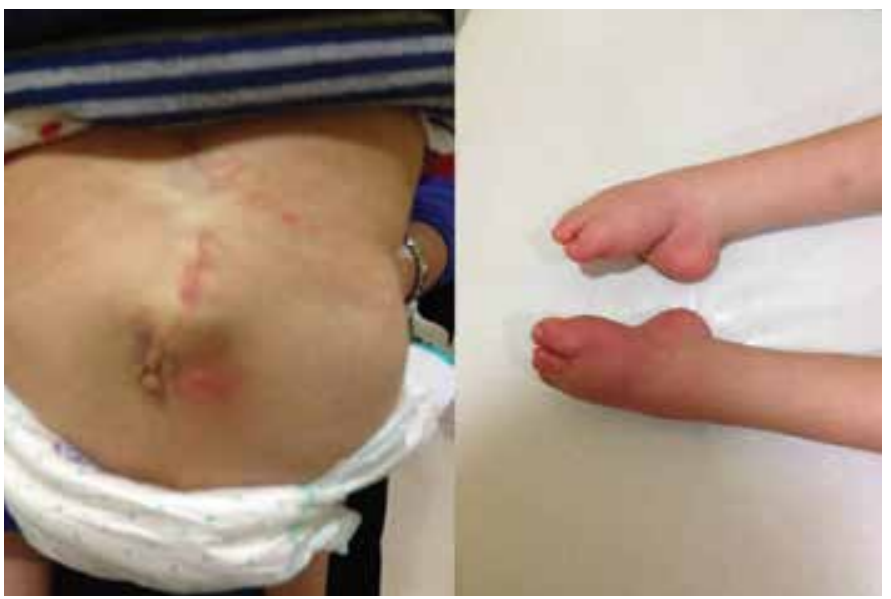

Figure 2. Vertebra and foot deformities

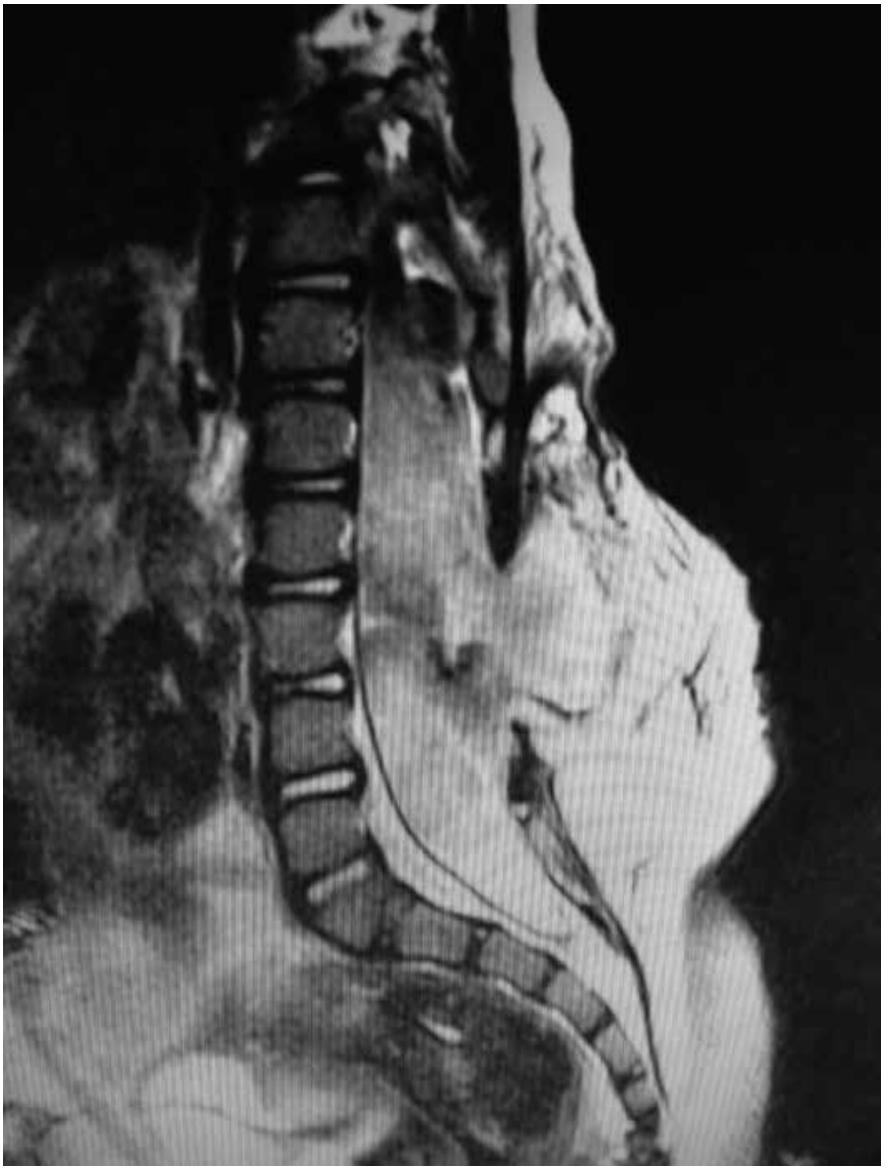

Figure 3. MRI of spina bifida aperta

Clinical pictures that differ depending on the motor involvement are observed in patients with SB. While only bladder and bowel dysfunction and/or denervation in intrinsic foot muscles are observed in mild cases with affected sacral segments, different levels of muscle weakness occur in the lower extremities in lumbar segment involvement. If the L2-L4 roots are strong, muscle strength is good in the knee extensors, which have a critical role for functional walking. Hip flexors and adductors are innerved from the L1-L2 roots. If these roots are protected, the patient can perform hip flexion. In contrast, in thoracic lesions, all roots innerving the muscles of the lower extremities are affected, and the legs are completely paralytic $(1,27)$.

Vertebral deformities and lower extremity contractures also negatively affect functional mobility. Therefore, these disorders should be detected during physical examination and then treated and followed up $(22,23)$.

In cases in which evaluation cannot be performed with a manual muscle test, the affected muscles can be examined by electromyography (EMG). In a study conducted with 50 children with SBO and 50 children with SBA, EMG revealed that the most frequently affected muscle was the tibialis anterior muscle in both of the groups. In the same study, while no clinical finding was observed or mild-moderate neurological deficit was detected in children with SBO, severe neurological involvement with many affected roots was found in children with SBA (28).

To determine the type and prevalence of lesions in patients with $\mathrm{SB}$, it is necessary to use imaging techniques. While plain radiography can demonstrate only osseous anomalies, more detailed data on lesions can be obtained with MRI (Figure 3). In suspicious situations with only skin findings, the diagnosis of SBO can be established with MRI $(29,30)$.

\section{Rehabilitation and Follow-up}

The aim of rehabilitation in patients with SB is to improve the quality of life and independence level of the individuals. The rehabilitation process begins from the neonatal period and lasts a lifetime. Because the people who will be with patients and care for them are the families of the patients during this period, rehabilitation must be family centered and must be planned taking the features of the family into consideration. In particular, caregivers must be informed regarding the clinical features of the disease and the points that require attention $(1,27)$.

These patients face many accompanying problems and complications during their lives. The most common of these include hydrocephaly and shunt complications, tethred cord, neurogenic bladder and bowel, compression wounds, hip dislocation, joint contractures, osteoporosis, learning disabilities, obesity, precocious puberty, latex allergy, and sexual problems. To prevent and treat these disorders, a rehabilitation program must be conducted by a team comprising various health workers, such as specialist physicians from related branches, physiotherapists, occupational therapists, speech therapists, nurses, and psychologists (31). Patients must be regularly followed up by a physical medicine and rehabilitation specialist from infancy. The use of standardized assessment instruments is recommended during these follow-ups. Some scales that allow patients to be evaluated from different perspectives, such as language, cognitive, and motor functions (for example, the BAYLEY-III Scale of Infant and Toddler Development), can be used beginning from early infancy. However, other scales, including the manual muscle test, provide good results only for children aged 5 years and above because they require the children to follow instructions. For defining the ambulation state, some scales, including Hoffer's classification system (community ambulation, home 
ambulation, therapeutic ambulation, and non-ambulatory), functional mobility scale, and Gross Motor Function Classification System, can be employed $(32,33)$. Owing to these scales, improvements and deteriorations in the clinical course of the patient can be revealed with greater certainty. The problems encountered should be minimized by obtaining support from related branches, when required, and attempts should be made to optimize the patient's quality of life and independence level.

\section{Exercise Program}

The exercise program of patients with SB must be organized according to the age and clinical state of the patients. In infants, developmental milestones, such as sitting and standing, must be followed, and early ambulation must be provided with exercises and orthosis $(1,26)$.

The absence of contractures in the lower extremities is a primary determinant of independent ambulation (23). Therefore, a passive range of motion exercises for the joints constitutes the base of exercise programs. For the joints, whose tendency to contracture is high because of muscle imbalance, stretching exercises must be added to the program; if necessary, positioning orthosis and casting must also be applied $(1,26,34)$. The improvement of muscle strength and endurance in weak regions is another primary goal of the exercise program. This improvement can be provided with classical strengthening exercises; positive results can be also obtained with electrical stimulation $(26,35)$. Because quadriceps muscle strength is very important for ambulation, this region must be intensely exercised in the treatment program (23).

\section{Ortheses}

The use of an appropriate orthosis provides improvements in ambulation for non-ambulatory patients and in parameters, such as energy consumption, walking speed, and step length for ambulatory patients $(36,37)$. Patients with SB can be evaluated in three groups according to their ambulation capacities and the ortheses they require. The first group includes patients with thoracic and high lumbar lesions. In these patients, the quadriceps is non-functional. While patients with hip flexion can be ambulated with hip-knee-ankle-foot orthoses or reciprocal gait orthoses, patients without hip flexion can be mobilized with parapodia. However, patients with this level of lesion usually use a wheelchair in adulthood. The second group comprises patients with moderate lumbar lesions. These patients can walk with knee-ankle-foot orthoses, ground reaction ankle-foot orthoses, or ankle-foot orthoses (AFO) according to their quadriceps muscle strengths. They are also ambulatory in the community in adulthood. The third group comprises patients with sacral lesions, almost all of whom can walk. This group can be divided into two subgroups: upper and lower sacral. While patients with upper sacral lesions can walk with AFO or foot orthoses, patients with lower sacral lesions can walk without an orthosis $(1,27,38)$.

Thoracolumbosacral orthoses can be used for spinal deformities. Although the efficiency of this orthosis in improving spinal deformity and in preventing its progression is controversial, it is recommended because it provides a functional position to patients and allows them to freely use their upper extremities $(1,39)$.

\section{Complications}

One of the points that should be considered in the rehabilitation of patients with SB is the prevention of complications. Urinary tract pathologies are frequently observed in these patients, and they require treatment with regular follow-up. The urinary system must be evaluated with US in the neonatal period and with voiding cystourethrography and urodynamics in the following periods. Necessary treatment arrangements, such as clean intermittent catheterization and drug therapy, must be done (40). Moreover, foot deformities and contractures in the lower extremity joints are among the most frequently observed complications. These make the use of orthoses and shoes more difficult and can cause compression wounds by negatively affecting ambulation. These deformities can be avoided by positioning, orthoses, and surgical intervention, when necessary (38). Another complication encountered in patients with SB is osteoporosis and related fractures. Therefore, in particular, patients with high-level lesions must be regularly evaluated with bone density measurements and bone metabolism markers for osteoporosis. Vitamin $\mathrm{D}$ and calcium preparations and weight-bearing exercises to the lower extremities can be recommended for treatment. There are not enough data on the use of bisphosphonates and other medical therapies in children (41). Compression wounds can also cause serious medical disturbances. Patients and families should be informed that the skin under the lesion is hypoesthesic/anesthesic and that they must control rashes and wounds in this region every day. Whether orthoses press against the skin or not and the state of the weight-bearing regions if the patient uses a wheelchair must be regularly controlled (42). When other problems, such as obesity, early puberty, and learning disabilities, are encountered during follow-up, related specialists must be consulted to help the patient overcome this problem (29).

Effective medical care and the prevention of complications reduce mortality and morbidity in SB. However, patients with SB who reach adulthood face various physical and social problems, including restrictions in independent living, sexual dysfunction, social isolation, and work-related issues (43). Although sexual dysfunction is primarily associated with the neurological level, it has been reported that the presence of incontinence, a lack of self-confidence, and hydrocephaly also negatively affect sex life $(44,45)$. In contrast, the factors affecting regular work have been reported to be educational level, lesion level, hydrocephaly, intelligence level, functional independence, and ambulation level (46).

\section{Conclusion}

The rehabilitation of SB is a process that must last a lifetime. With a family centered and multidisciplinary approach, this process can be continued efficiently and a quality life can be provided to the patient.

\section{Peer-review: Externally peer-reviewed.}

Conflict of Interest: No conflict of interest was declared by the author.

Financial Disclosure: The author declared that this study has received no financial support. 


\section{References}

1. Pico EL, Wilson PE, Haas R. Spina bifida. In: Alexander MA, Matthews DJ, editors. Pediatric rehabilitation. 4th ed. New York, USA: Demos Medical Publishing;2010.p. 199-230.

2. Rossi A, Biancheri R, Cama A, Piatelli G, Ravegnani M, Tortori-Donati P. Imaging in spine and spinal cord malformations. Eur J Radiol 2004;50:177-200. [CrossRef]

3. Copp AJ, Greene ND. Neural tube defects--disorders of neurulation and related embryonic processes. Wiley Interdiscip Rev Dev Biol 2013; 2:213-27. [CrossRef]

4. Gupta P, Kumar A, Kumar A, Goel S. Congenital spinal cord anomalies: a pictorial review. Curr Probl Diagn Radiol 2013;42:57-66. [CrossRef]

5. Centers for Disease Control and Prevention (CDC). Racial/ethnic differences in the birth prevalence of spina bifida - United States, 1995-2005. MMWR Morb Mortal Wkly Rep 2009;57:1409-13.

6. Au KS, Ashley-Koch A, Northrup H. Epidemiologic and genetic aspects of spina bifida and other neural tube defects. Dev Disabil Res Rev 2010;16:6-15. [CrossRef]

7. Onrat ST, Seyman H, Konuk M. Incidence of neural tube defects in Afyonkarahisar, Western Turkey. Genet Mol Res 2009;8:154-61. [CrossRef]

8. Fisk Green R, Byrne J, Crider KS, Gallagher M, Koontz D, Berry RJ. Folate-related gene variants in Irish families affected by neural tube defects. Front Genet 2013;4:223. [CrossRef]

9. Lembet A, Uğurlu EN, Toprak T, Bastu E. Rare case of spina bifida in both twins with possible genetic basis. J Obstet Gynaecol Res 2011;37:1755-8. [CrossRef]

10. Osterhues A, Ali NS, Michels KB. The role of folic acid fortification in neural tube defects: a review. Crit Rev Food Sci Nutr 2013;53:1180-90. [CrossRef]

11. Trudell AS, Odibo AO. Diagnosis of spina bifida on ultrasound: Always termination? Best Pract Res Clin Obstet Gynaecol 2014;28:367-77. [CrossRef]

12. Buyukkurt S, Binokay F, Seydaoglu G, Gulec UK, Ozgunen FT, Evruke $C$, et al. Prenatal determination of the upper lesion level of spina bifida with three-dimensional ultrasound. Fetal Diagn Ther 2013;33:36-40. [CrossRef]

13. Aygün C, Kurucu S, Cakmak Çelik F, Dağçınar A, Tanyeri B, Küçüködük $S$. Experience of a tertiary care center on 100 newborns with neural tube defects. Turk J Pediatr 2013;55:359-64.

14. Ben-Sira L, Garel C, Malinger G, Constantini S. Prenatal diagnosis of spinal dysraphism. Childs Nerv Syst 2013;29:1541-52. [CrossRef]

15. Danzer $E$, Johnson MP. Fetal surgery for neural tube defects. Semin Fetal Neonatal Med 2014;19:2-8. [CrossRef]

16. American College of Obstetricians and Gynecologists. ACOG Committee opinion no. 550: maternal-fetal surgery for myelomeningocele. Obstet Gynecol 2013;121:218-9.

17. Luthy DA, Wardinsky T, Shurtleff DB, Hollenbach KA, Hickok DE, Nyberg DA, et al. Cesarean section before onset of labor and subsequent motor function in infant with meningomyelocele diagnosed antenally. N Engl J Med 1991;324:662-66. [CrossRef]

18. Bowman RM, McLone DG. Neurosurgical management of spina bifida: research issues. Dev Disabil Res Rev 2010;16:82-7. [CrossRef]

19. Lewis D, Tolosa JE, Kaufmann M, Goodman M, Farrell C, Berghella V. Elective cesarean delivery and long-term motor function or ambulation status in infants with meningomyelocele. Obstet Gynecol 2004; 103:469-73. [CrossRef]

20. Thompson DN. Postnatal management and outcome for neural tube defects including spina bifida and encephalocoeles. Prenat Diagn 2009;29:412-9.[CrossRef]

21. Elgamal EA. Natural history of hydrocephalus in children with spinal open neural tube defect. Surg Neurol Int 2012;3:112. [CrossRef]

22. Danielsson AJ, Bartonek A, Levey E, McHale K, Sponseller P, Saraste $H$. Associations between orthopaedic findings, ambulation and health-related quality of life in children with myelomeningocele. J Child Orthop 2008;2:45-54. [CrossRef]
23. Schoenmakers MA, Uiterwaal CS, Gulmans VA, Gooskens RH, Helders PJ. Determinants of functional independence and quality of life in children with spina bifida. Clin Rehabil 2005;19:677-85. [CrossRef]

24. Brand MC. Part 3: examination of the newborn with closed spinal dysraphism. Adv Neonatal Care 2007;7:30-40. [CrossRef]

25. Rademacher N, Black DP, Ulrich BD. Early spontaneous leg movements in infants born with and without myelomeningocele. Pediatr Phys Ther 2008;20:137-45. [CrossRef]

26. Hinderer KA, Hinderer SR, Shurtleff DB. Myelodysplasia. In: Campbell SK, Linden DWV, Palisano RJ, editors. Physical therapy for children. 3rd ed. Missouri, USA: Saunders Elsevier; 2006. p. 735-89.

27. Rossi R, Alexander M, Cuccurullo S. Pediatric Rehabilitation. In: Cuccurullo S, editor. Physical Medicine and Rehabilitation Board Review. New York, USA: Demos Medical Publishing;2004. p.645-742.

28. Petronic I, Nikolic D, Cirovic D, Cvjeticanin S, Knezevic T, Raicevic M, et al. Distribution of affected muscles and degree of neurogenic lesion in patients with spina bifida. Arch Med Sci 2011;7:1049-54. [CrossRef]

29. Chiu HY, Liao YH. Images in clinical medicine. Occult spinal dysraphism. N Engl J Med 2014;370:466. [CrossRef]

30. Pires CR, de Medeiros JM, Araujo Júnior E, Czapkowski A, Zanforlin Filho SM. Occult spinal dysraphism in the presence of rare cutaneous stigma in a neonate: importance of ultrasound and magnetic resonance imaging. Case Rep Med 2013;468376. [CrossRef]

31. Liptak GS, El Samra A. Optimizing health care for children with spina bifida. Dev Disabil Res Rev 2010;16:66-75. [CrossRef]

32. Bayley N. Bayley Scales of Infant and Toddler Development. 3rd edn. San Antonio, TX: Harcourt Assessment Inc, 2006.

33. Vladusic S, Phillips D. Independence in Mobility. In:Özek MM, Cinalli G, Maixner W], editors. Spina bifida management and outcome. Milan, Italy:Springer-Verlag;2008.p.349-80. [CrossRef]

34. Al-Oraibi S, Tariah HA, Alanazi A. Serial casting versus stretching technique to treat knee flexion contracture in children with spina bifida: a comparative study. J Pediatr Rehabil Med 2013;6:147-53.

35. Karmel-Ross K, Cooperman DR, Van Doren CL. The effect of electrical stimulation on quadriceps femoris muscle torque in children with spina bifida. Phys Ther 1992;72:723-30.

36. Duffy CM, Graham HK, Cosgrove AP. The influence of ankle-foot orthoses on gait and energy expenditure in spina bifida. J Pediatr Orthop 2000;20:356-61. [CrossRef]

37. Katz-Leurer M, Weber C, Smerling-Kerem J, Rottem H, Meyer S. Prescribing the reciprocal gait orthosis for myelomeningocele children: a different approach and clinical outcome. Pediatr Rehabil 2004;7:105-9. [CrossRef]

38. Swaroop VT, Dias L. Orthopedic management of spina bifida. Part I: hip, knee, and rotational deformities. J Child Orthop 2009;3:441-9. [CrossRef]

39. Allam AM, Schwabe AL. Neuromuscular scoliosis. PM R 2013;5:957-63. [CrossRef]

40. Clayton DB, Brock JW 3rd, Joseph DB. Urologic management of spina bifida. Dev Disabil Res Rev 2010;16:88-95. [CrossRef]

41. Marreiros HF, Loff C, Calado E. Osteoporosis in paediatric patients with spina bifida. J Spinal Cord Med 2012;35:9-21. [CrossRef]

42. Ekmark EM. Risky business: Preventing skin breakdown in children with spina bifida. J Pediatr Rehabil Med 2009;2:37-50.

43. Roach JW, Short BF, Saltzman HM. Adult consequences of spina bifida: a cohort study. Clin Orthop Relat Res 2011;469:1246-52. [CrossRef]

44. Verhoef M, Barf HA, Vroege JA, Post MW, Van Asbeck FW, Gooskens RH, et al. Sex education, relationships, and sexuality in young adults with spina bifida. Arch Phys Med Rehabil 2005;86:979-87. [CrossRef]

45. Bong GW, Rovner ES. Sexual health in adult men with spina bifida. ScientificWorldJournal 2007;7:1466-9. [CrossRef]

46. van Mechelen MC, Verhoef $M$, van Asbeck FW, Post MW. Work participation among young adults with spina bifida in the Netherlands. Dev Med Child Neurol 2008;50:772-7. [CrossRef] 